Jurnal Pendidikan Ekonomi: Jurnal Ilmiah Ilmu Pendidikan, Ilmu Ekonomi, dan Ilmu Sosial ISSN 1907-9990 | E-ISSN 2548-7175 | Volume 11 Nomor 1 (2017)

\title{
PROFIL WANITA PEKERJA DI PABRIK SARDEN PT. MAYA DESA KEDUNGREJO KECAMATAN MUNCAR KABUPATEN BANYUWANGI
}

\author{
Aginta Nortadhoh ${ }^{1}$, Sri Wahyuni ${ }^{1}$, Bambang Suyadi ${ }^{1}$ \\ ${ }^{1}$ Program Studi Pendidikan Ekonomi, Fakultas Keguruan dan Ilmu Pendidikan, Universitas Jember
}

\begin{abstract}
The purpose of this study is to find characteristic of a woman workers, picture in a public sector and sector domestic, marginalisasi, and allocation of time working woman. Characteristic of a woman workers in this research seen from age working woman, status marriage, the number of dependents children, and length of employment which will would bring them to different characters with the woman not worked so as bring up motiv its own for women workers. To know picture working woman in a public sector and sector domestic. Marginalisasi woman workers at a factory sardines Maya Kedungrejo Muncar Banyuwangi intended here differences in placement a position between working man with working woman. Allocation of time intended here to see how working woman set time to work in a factory, doing his job as a housewife, and when they with the community about his house. The kind of research this is the qualitative study. Research locations determined by means of purposive the area that carried out in a factory sardines PT. Maya Kedungrejo Muncar Banyuwangi. Data were collected by using the method observation, interview, the literature study, and documentation. Informants in this research was workers woman who works in a mill PT. Maya Kedungrejo Muncar. Data analysis used, namely analysis research descriptive qualitative. The research results show that characteristic of a woman workers in a factory Maya Kedungrejo Muncar are women those who has married, with families to, the husband is work and become the backbone of family, and women who still carrying out their obligations as a housewife namely the house, husband, and their children. Woman working on public sector tends to be dominant than domestic for the sectors. Woman workers at a factory sardines maya there are still many work in position production so marginalisasi on workers women still very looked. In the allocation of their time affecting income that they can.
\end{abstract}

Keywords: The profile of women, characteristics, public and domestic, marginalisasi, allocation of time

\section{PENDAHULUAN}

Secara geografis, kabupaten Banyuwangi terletak diujung timur Pulau Jawa dan memiliki pesisir pantai yang panjang $\pm 175,8 \mathrm{Km}$, Kecamatan Muncar merupakan Kecamatan yang berada dikawasan selatan wilayah Kabupaten Banyuwangi $\pm 76,90 \mathrm{Km}$. Banyaknya pabrik sarden yang berdiri di daerah Muncar seperti Avila, Blambangan, Sumber Yalasamudra, dan PT. Maya, dalam penelitian ini adalah PT. Maya. PT Maya Muncar merupakan salah satu perusahaan yang ada disana, PT. Maya Muncar adalah sebuah industry pengalengan ikan (pabrikase) yang menghasilkan olahan ikan dalam kaleng bernama "Maya \& Three Folwers" berupa ikan sardines dan makarel. Lokasi pabrik berada di Dukuh Sampangan Muncar Desa Kedungrejo Kecamatan Muncar Banyuwangi. Tanah yang ditempati seluas 13,840 $\mathrm{M}^{2}$. Jumlah pegawai 673 orang yang didominasi lebih banyak Wanita. Pekerja wanita banyak dipekerjakan di bagian pemotongan ikan, trimming, pengisian dalam kaleng (filling), pengelapan, pelabelan, dan pembongkaran gudang yang dilakukan dengan sistem harian. 
Tabel 1. Jumlah Pegawai Pabrik Maya

\begin{tabular}{|l|l|r|r|}
\hline No & \multicolumn{2}{|c|}{ Pegawai Pabrik Sarden } & $\%$ \\
\hline 1 & Wanita & 553 & $82,2 \%$ \\
\hline 2 & Laki-laki & 120 & $17,8 \%$ \\
\hline \multicolumn{2}{|c|}{ Jumlah } & 673 & $100 \%$ \\
\hline
\end{tabular}

Sumber: Data Pekerja Pabrik Maya

Tabel di atas jumlah pegawai wanita mencapai $82,2 \%$ dan laki - laki hanya 17,8 \%, wanita lebih mendominasi Laki - laki dari data di atas. Pabrik sengaja menempatkan lebih banyak pekerja wanita karena pekerjaan pengolahan ikan lebih mementingkan skill ketelatenan yang biasanya wanita lebih terampil dari pada laki-laki. Tenaga kerja wanita yang bekerja di pabrik dengan sistem harian juga dinilai menguntungkan pekerja wanita karena tidak terikat oleh waktu. Jika mereka memilih untuk mendapatkan pendapatan yang lebih banyak maka bisa menambah jam kerja dan menambah pekerjaan selama stok ikan yang tersedia juga masih ada untuk di produksi. Pabrik juga tidak memberikan kriteria adsministrasi yang rumit untuk bekerja di pabrik sarden Maya. Tingkat pendidikan, umur, dan status pernikahan tidak dipermasalahkan untuk bekerja diposisi ini. Namun upah yang tersedia minim jika dibandingkan dengan beban kerja dan jam kerja yang diberikan pabrik kepada wanita pekerja. Namun hal ini tidak menyurutkan pekerja wanita untuk tetap antusias bekerja. Berdasarkan wawancara dengan salah satu Wanita pekerja sebagai berikut:

"bersyukur bisa kerja disini mas padahal saya hanya lulusan SMP, meskipun gajinya kecil tapi sudah bisa membantu suami)." $\mathrm{KM}^{45 t h}$

Wanita pekerja tetap merasa beruntung memiliki pekerjaan ini jika mengingat jenjang pendidikan yang mereka miliki rata-rata hanya lulusan SMP, karena alasan ketelatenan dan tingkat pendidikan rendah yang membuat perusahaan menempatkan wanita pekerja diposisi ini. Hal ini diperkuat dengan pendapat Bambang dan Mukhlis (2006) dari hasil penelitiannya yang mengatakan alasan lain yang dapat menyebabkan wanita memilih bekerja di sektor informal adalah tidak tersedianya lapangan pekerjaan yang sesuai dengan tingkat pendidikan mereka. Penduduk lulusan SMP tersebut hanya bisa bekerja seadanya seperti menjadi buruh di pabrik sarden dan tentunya dengan penghasilan yang rendah.

Penelitian mengenai pendapatan wanita dan kontribusinya pernah dilakukan oleh Kurniawati (2008), dari hasil penelitian tersebut diperoleh tingkat pendidikan dan jenis pekerjaan berpengaruh nyata terhadap pendapatan wanita. Penelitian sebelumnya juga dilakukan oleh Sari (2010) menemukan bahwa umur, status perkawinan, dan pendidikan berpengaruh terhadap pekerja wanita sektor informal. Meningkatnya jumlah anak yang dimiliki, maka meningkat pula beban tanggungan keluarga tersebut sehingga mengharuskan anggota keluarga lain selain kepala keluarga untuk membantu mencari nafkah. Tingkat besar kecilnya pendapatan yang diterima oleh tenaga kerja wanita ini berpengaruh terhadap pemanfaatan pendapatan yang diberikan kepada keluarganya. Semakin besar tingkat pendapatan yang diterima oleh tenaga kerja wanita ini maka semakin besar pula tingkat pemanfaatan pendapatan yang diberikan kepada keluarga.

Wanita yang bekerja di pabrik sarden Maya Muncar mayoritas telah berkeluarga dan memiliki anak. Jam kerja yang panjang yakni sekitar 8 jam jika stok ikan pada keadaan normal 
(tidak ada penambahan stok). Setiap pagi wanita pekerja akan dijemput truk pabrik jam 06.30 WIB, mulai bekerja jam 07.00 WIB, normalnya mereka pulang jam $16.00 \mathrm{WIB}$, dan jam pulang mereka bisa sampai jam 20.00 WIB atau lebih (tergantung jumlah ikan). Pendapatan dan jam kerja wanita pekerja pabrik sarden Maya sejalan dengan jumlah ikan yang diproduksi, jika ikan yang diproduksi banyak maka pendapatan mereka juga banyak serta jam kerja juga lebih panjang. Kendati waktu mereka tercurahkan sebagian di pabrik namun kehidupan keluarga mereka tetap harmonis, hal ini menjadi menarik untuk diteliti.

Beban kerja pabrik, beban pekerjaan rumah, dan figure sebagai istri wanita dan pekerja menjadikan wanita pekerja memiliki karakteristik unik jika dibandingkan dengan wanita yang tidak bekerja. Wanita pekerja di pabrik Maya juga mengaku betah dan senang bekerja di pabrik Maya. Pabrik Maya Muncar dinilai cukup memberikan kontribusi bagi kehidupan wanitapekerja di pabrik Maya Muncar. Banyaknya pekerja wanita yang bekerja di pabrik ini dan capaian pabrik Maya untuk menjadi salah satu industri yang dapat membantu menopang kehidupan masyarakat di sekitar pabrik membuat pabrik ini menjadi menambah ketertarikan peneliti untuk mengetahui lebih lanjut kontribusi dalam bentuk apa yang nyata diberikan pabrik bagi keluarga wanita pekerja pada khususnya dan masyarakat Muncar pada umumnya.

Wanita yang bekerja memiliki karakteristik yang berbeda dan peran yang berbeda jika dibandingkan dengan wanita yang hanya menghabiskan waktu di rumah. Wanita pekerja memiliki andil yang cukup besar dalam membantu suami mencari nafkah. Tugas wanita pekerja bertambah seiring bertambahnya peran pekerjaan yang dilakoni. Keadaan ini menjadi sangat menarik untuk diteliti, profil wanita pekerja yang berbeda dan khas, manajemen waktu dalam melakoni pekerjaan di pabrik diluar tugas utama wanita di dalam rumah tangga. Kontribusi wanita dalam membantu suami untuk mencari nafkah, usaha - usaha yang dilakukan wanita pekerja agar rumah tangganya harmonis meski harus menghabiskan sebagian waktu di pabrik membuat wanita pekerja mempunyai dimensi dan karakter yang berbeda dengan wanita yang tidak bekerja.

Berdasarkan pemaparan di atas maka peneliti tertarik untuk melakukan penelitian dengan judul "Profil Wanita Pekerja Di Pabrik Sarden PT. Maya Desa Kedungrejo Kecamatan Muncar Kabupaten Banyuwangi".

\section{METODE PENELITIAN}

Pendekatan dalam penelitian ini menggunakan pendekatan kualitatif. Peneliti melakukan penelitian di pabrik sarden Maya Desa Kedungrejo Kecamatan Muncar kabupaten Banyuwangi. Tentang profil wanita yang bekerja di pabrik sarden Maya Muncar. Metode pengumpulan data yang digunakan adalah metode observasi, wawancara, studi pustaka, dan dokumentasi. Observasi dilakukan untuk mencari data mengenai kondisi ekonomi, marginalisasi, alokasi waktu, motif kerja, dan karakteristik wanita yang meliputi: Umur, pendidikan, jenis pekerjaan, status pernikahan, masa kerja. Wawancara dilakukan untuk mengetahui profil pekerja wanita pabrik sarden maya Desa Kedung Rejo Muncar dapat dilihat dari karakteristik umum wanita pekerja seperti umur, tingkat pendidikan, dan status perempuan dalam pabrik. Lebih lanjut wawancara juga mengumpulkan informasi mengenai gambaran pekerjaan yang dilakukan wanita pekerja di pabrik sarden Maya dalam produksi sarden serta kontribusi pabrik Maya pada kehidupan wanita pekerja di pabrik Maya Muncar. Studi pustaka 
dilakukan dengan mencari referensi di berbagai buku dan hasil penelitian terdahulu. Dokumentasi yang digunakan meliputi keadaan pabrik Maya Desa Kedung Rejo Kecamatan Muncar, hasil rekap rekaman wawancara dengan informan, data-data lain yang mendukung.

Metode analisis data yang digunakan adalah deskriptif kualitatif. Instrumen yang digunakan berupa pedoman wawancara (guide interview) yang berisikan daftar pertanyaan mengenai dua aspek yang diteliti, yaitu profil wanita pekerja yang membahas mengenai karakteristik wanita, motif bekerja, alokasi waktu, dan marginalisasi pada wanita yang bekerja di pabrik sarden Maya. Selain itu peneliti juga membahas mengenai marginalisasi dan alokasi waktu yang dicurahkan pekerja wanita untuk melakoni perannya

\section{HASIL DAN PEMBAHASAN \\ Hasil Penelitian}

Hasil penelitian ini menunjukkan bahwa wanita yang bekerja di pabrik Sarden Maya Desa Kedungrejo Kecamatan Muncar Kabupaten Banyuwangi merupakan ibu rumah tangga yang memiliki anak, serta suami yang juga masih bekerja. Dalam hal ini wanita yang bekerja tersebut bukanlah tulang punggung keluarga, melainkan hanya membantu suami dalam memenuhi kebutuhan keluarga. Wanita yang bekerja juga tidak mengesampingkan tugasnya sebagai ibu yaitu mengurus anak-anak mereka, mereka juga ikut andil dalam mencari nafkah akan tetapi mereka bukanlah tulang punggung keluarga, melainkan hanya membantu suami dalam memenuhi kebutuhan keluarga. bagian produksi pabrik sarden Maya di Desa Kedungrejo Kecamatan Muncar Kabupaten Banyuwangi lebih banyak membutuhkan tenaga kerja perempuan daripada tenaga kerja laki-laki. Hal ini dikarenakan pada proses produksi pabrik sarden tersebut membutuhkan ketelatenan, seperti saat pengguntingan, pengisian, pemasakan awal, penghampaan, penutupan wadah kaleng, pendinginan dan pengepakan.

Wanita pekerja di pabrik sarden maya merupakan wanita yang sudah berkeluarga, memiliki tanggungan keluarga, memiliki suami yang bekerja dan menjadi tulang punggung keluarga, dan wanita yang masih tetap melaksanakan kewajibannya sebagai ibu rumah tangga yaitu mengurus rumah, suami, dan anak-anak mereka. Motif mereka memilih bekerja untuk membantu suami dalam memenuhi kebutuhan keluarga serta biaya sekolah anak-anak mereka. Wanita pekerja di pabrik Sarden PT. Maya Desa Kedungrejo Kecamatan Muncar Kabupaten Banyuwangi memiliki waktu bekerja di sektor publik yang lebih dominan dibanding waktu yang digunakan untuk sektor domestic. Wanita pekerja pasti harus bisa mengatur waktunya agar semua peran yang disandangnya dapat dilaksanakan dengan seimbang. Wanita yang bekerja disektor publik pasti tidak memiliki banyak waktu luang untuk mengurus suami dan anak, maka dari itu wanita yang terjun ke sektor publik pastilah memerlukan dukungan dari anak - anaknya dan juga suami mereka, seperti wanita pekerja di pabrik sarden PT. Maya Desa Kedungrejo Kecamatan Muncar Kabupaten Banyuwangi yang selalu mendapatkan dukungan dari suami dan anak - anaknya. Kegiatan rumah tangga yang tidak sempat dilakukan oleh wanita pekerja pada saat bekerja bisa digantikan oleh suami dan anak - anak mereka. 


\section{Pembahasan}

1. Karakteristik wanita pekerja

Wanita yang bekerja di pabrik Sarden Maya Desa Kedungrejo Kecamatan Muncar Kabupaten Banyuwangi merupakan ibu rumah tangga yang memiliki anak, serta suami yang juga masih bekerja. Dalam hal ini wanita yang bekerja tersebut bukanlah tulang punggung keluarga, melainkan hanya membantu suami dalam memenuhi kebutuhan keluarga. Wanita yang bekerja juga tidak mengesampingkan tugasnya sebagai ibu yaitu mengurus anak-anak mereka.

2. Wanita Sebagai Pencari Nafkah

Wanita yang bekerja di pabrik Sarden Maya Desa Kedungrejo Kecamatan Muncar Kabupaten Banyuwangi memutuskan untuk bekerja karena ada keinginan untuk membantu suami dalam memenuhi kebutuhan sehari-hari, keadaan kekurangan atau miskin, dan untuk pendidikan anak-anak. Sehingga dalam hal ini wanita yang bekerja dikarenakan adanya tuntutan kebutuhan yang harus dipenuhi oleh wanita tersebut.

3. Wanita di Sektor Industri

Pekerja wanita cukup banyak memberikan peranan dalam proses produksi tersebut di pabrik sarden Maya di Desa Kedungrejo Kecamatan Muncar Kabupaten Banyuwangi. Hal ini dikarenakan ada beberapa bagian dalam proses produksi seperti bagian pengguntingan dan pengisian yang memang lebih cocok dilakukan oleh buruh wanita. Oleh karena itulah pada bagian produksi tersebut lebih banyak terdapat buruh wanita. Hal ini menunjukkan bahwa pada pabrik Sarden Maya Desa Kedungrejo Kecamatan Muncar terjadi marginalisasi buruh wanita. Hal tersebut dapat dilihat dari adanya pembagian tugas yang masih memperhatikan gender para tenaga kerja. Dimana untuk tenaga kerja laki-laki biasanya akan memperoleh bagian yang lebih berat dari pada perempuan. Hal ini memang dimaksudkan untuk memperlancar suatu proses produksi agar berjalan dengan lancar, karena dengan penempatan tenaga kerja perempuan dan laki-laki yang tepat, maka dapat dihasilkan proses produksi yang lancar dan maksimal. Dapat disimpulkan wanita yang terjun ke sektor industri atau sektor publik akan mendapatkan perlakuan yang berbeda, atau adanya marginalisasi ditempat mereka bekerja.

4. Wanita Sebagai Ibu Rumah Tangga

Wanita pekerja sebelum berangkat kerja mereka tidak melupakan kewajibannya sebagai ibu rumah tangga dengan selalu menyiapkan sarapan dan perlengkapan sekolah anak -anak mereka meskipun setelah itu mereka harus berangkat bekerja. Mereka akan langsung pulang kerumah jika tidak lembur kerja, mereka akan melakukan kegiatan rumah tangga seperti membersihkan rumah dan mencuci piring. Setelah itu mereka akan beristirahat untuk melakukan kegiatan esok harinya. Jika mereka libur bekerja mereka akan mengunakan waktu luangnya untuk mencuci baju bercengkrama dengan tetangga atau melakukan kegiatan rumah tangga yang tidak sempat mereka lakukan pada saat mereka bekerja.

5. Wanita Pekerja dalam Sektor Publik dan Sektor Domestik

Wanita cenderung lebih dominan bekerja di sektor publik dibanding waktu yang digunakan untuk sektor domestik. Wanita pekerja pasti harus bisa mengatur waktunya agar semua peran yang disandangnya dapat dilaksanakan dengan seimbang. Wanita yang bekerja 
disektor publik pasti tidak memiliki banyak waktu luang untuk mengurus suami dan anak, maka dari itu wanita yang terjun ke sektor publik pastilah memerlukan dukungan dari anak - anaknya dan juga suami mereka, seperti wanita pekerja di pabrik sarden PT. Maya Desa Kedungrejo Kecamatan Muncar Kabupaten Banyuwangi yang selalu mendapatkan dukungan dari suami dan anak - anaknya. Kegiatan rumah tangga yang tidak sempat dilakukan oleh wanita pekerja pada saat bekerja bisa digantikan oleh suami dan anak anak mereka.

6. Marginalisasi Wanita Pekerja

Pada bagian produksi pabrik Sarden Maya di Desa Kedungrejo Kecamatan Muncar terdapat marginalisasi tenaga kerja. Hal tersebut dapat dilihat dari adanya pembagian tugas yang masih memperhatikan gender para tenaga kerja. Dimana untuk tenaga kerja laki-laki biasanya akan memperoleh bagian yang lebih berat dari pada perempuan. Hal ini memang dimaksudkan untuk memperlancar suatu proses produksi agar berjalan dengan lancar, karena dengan penempatan tenaga kerja perempuan dan laki-laki yang tepat, maka dapat dihasilkan proses produksi yang lancar dan maksimal.

7. Alokasi Waktu Wanita Pekerja

Alokasi waktu wanita pekerja di tempat kerja mempengaruhi pendapatan wanita. Sangatlah menguntungkan bagi wanita pekerja karena waktu kerja yang dikeluarkan oleh pekerja wanita sebanding dengan pendapatan yang diperoleh. Akan tetapi waktu yang digunakan bersama keluarga berkurang untuk mengurus keluarga karena waktu mereka tersita untuk bekerja di pabrik. Pada saat libur kerja pekerja wanita memilih untuk bersosialisasi dengan masyarakat, yakni saat dipabrik sedang kehabisan stock ikan, jadi para pekerja wanita akan mendapatkan hari libur sampai pabrik mendapatkan stock ikan lagi.

\section{KESIMPULAN DAN SARAN}

\section{Kesimpulan}

Berdasarkan hasil penelitian yang telah dilakukan di Pabrik Sarden Maya Desa Kedungrejo Kecamatan Muncar Kabupaten Banyuwangi, peneliti menarik kesimpulan yang pertama, karakteristik wanita Pekerja dipabrik Maya Desa Kedungrejo Kecamatan Muncar merupakan wanita yang sudah berkeluarga, memiliki tanggungan keluarga, memiliki suami yang bekerja dan menjadi tulang punggung keluarga, dan wanita yang masih tetap melaksanakan kewajibannya sebagai ibu rumah tangga yaitu mengurus rumah, suami, dan anak-anak mereka. Kedua, wanita pekerja di sektor publik cenderung lebih dominan dibanding untuk sektor domestik. Ketiga, wanita pekerja di pabrik sarden Maya masih banyak bekerja di posisi produksi sehingga marginalisasi pada pekerja wanita masih sangat tampak.

\section{Saran}

Melihat profil wanita pekerja, saran yang dapat peneliti sampaikan kepada beberapa pihak, antara lain: Pertama, pabrik Sarden Maya Desa Kedungrejo. Untuk lebih memperhatikan beban kerja yang diberikan kepada karyawan dan menyesuaikan upah yang diberikan.. Kedua, wanita pekerja. Agar ebih giat dalam bekerja dan membantu suami untuk pemenuhan kebutuhan keluarga, serta terus menjalankan kewajibannya sebagai istri dan ibu. Ketiga, suami 
wanita pekerja. Hendaknya mencari pekerjaan tambahan lain agar dapat meningkatkan pendapatan guna mencukupi kebutuhan keluarga.

\section{DAFTAR BACAAN}

Denrich Suryadi, et al. 2004. Gambaran Konflik Emosional dalam Menentikan Prioritas Peran Ganda. Jurnal Ilmiah Psikologi. Arkhe 1.

Irawan, P. 2006. Penelitian Kualitatif dan Kuantitatif untuk Ilmu-Ilmu Sosial. Depok: Departemen Ilmu Administrasi Fakultas Ilmu Sosial dan Ilmu Politik Universitas Indonesia.

Jember University Press. 2012. Pedoman Penulisan Karya Ilmiah Universitas Jember. Jember: Jember University Press.

Kurnia wati, Nuning 2008. Analisis Faktor-Faktor Yang Mempengaruhi Pendapatan Perempuan dan Kontribusinya Terhadap Pendapatan Keluarga Miskin Di Kelurahan Penatih Kecamatan Denpasar Timur Kota Denpasar. Skripsi. Sarjana Fakultas Ekonomi Universitas Udayana, Denpasar.

Pratiwi, Eka. 2012. Peran Ganda Perempuan Studi tentang Buruh Tani di Desa Mulo, Wonosari. Gunung Kidul. Skripsi. FSIP UIN Sunan Kalijaga: Yogjakarta.

Rustiani, F., 1996, "Istilah-Istilah Umum dalam Wacana Gender”, dalam Jurnal Showalter, E., (ed), 1989, Speaking of Gender, Routledge, New York \& London.

Sukamto, Andreas. 2014. Kontribusi pekerja perempuan terhadappembentukan pendapatan keluarga. Skripsi. Prodi Ekonomi Pembangunan Universitas Atma Jaya: Yogyakarta.

Suharto, E. 2007. Kebijakan sosial sebagai kebijakan publik. Bandung: Alfabeta.

Walgito, B. Pengantar Psikologi Umum.Ed. 3. Yogyakarta: Adi; 2002 